\title{
On the validity of scalp recordings of the auditory evoked potential'
}

\author{
J. PETER ROSENFELD² AND ALAN P. RUDELL \\ UNIVERSITY OF IOWA
}

\begin{abstract}
Simultaneous recording from scalp and cortical electrodes in unanesthetized and unrestrained cats revealed essentially no differences between the superficial and deep recordings of the auditory evoked responses. Human recordings taken under two conditions of muscular contraction contained no major differences from 30 to 300 msec after stimulus onset.
\end{abstract}

Following an experiment in which the amplitude of a late component of the cat's visual evoked potential was operantly conditioned (Fox \& Rudell, 1968), our laboratory is attempting to bring a component of the human auditory evoked response under operant control. Until the study reported here was completed, however, we were concerned that the claim to have brought under reinforcement control, a neural event recorded from human scalp and evoked by auditory stimuli, was questionable inasmuch as a recent review (Bergamini \& Bergamasco, 1967), warned that several studies (Bickford et al, 1964; Davis et al, 1964; Jacobson et al, 1964), have "... proved that the acoustic evoked potential does not really represent cortical activity but rather a 'sonomotor' myogenic response due to vestibular receptors which provoke a response from the extrinsic auricular and temporal muscles." Not intending, in our operant studies, to condition a myogenic artifact, it was important that the auditory response recorded from human scalp be of a genuine and reliable cortical origin. The work reported here attempts to help establish that fact by (1) simultaneously recording from scalp and deep electrodes, the latter placed in four acknowledged auditory receiving areas in cat cortex, and (2) recording human auditory evoked responses under two conditions of muscle tension, as has been done before (Bickford et al, 1964), but focusing our attention upon the later components of the disputed potential.

The near identity of cortical somatosensory evoked responses with scalp recordings has been repeatedly demonstrated (Jasper et al, 1960; Hirsch et al, 1961; Domino et al, 1964); the validity of the scalp-recorded visual evoked response has likewise been established (Cooper et al, 1965; Katzman, 1964; Domino \& Corssen, 1964). The evidence for identical scalp and deep auditory evoked responses is neither as clear nor as complete. Evoked responses have indeed been reported from human auditory cortex (Chatrian et al, 1960), and in fact, a recent study (Celesia et al, 1968), supplemented deep recordings with scalp recordings, but in this latter report the deep and scalp recordings were taken at different times, and the deep potentials were observed in auditory cortex following temporal lobotomy. Nevertheless, the major components of scalp and deep records corresponded, although differences in peak latencies and phase relations marred the identity. Moreover, the phase differences were not consistent: scalp led cortex (unexpectedly) in the early portion of the epoch whereas the reverse was true at the end of the epoch. The authors were conservative about the degree of correspondence between scalp and deep records; they suggested the possibility that myogenic contamination of the scalp record could account for the differences. (Ruhm \& Flanigin, 1967, recorded from scalp and deep sites in man and obtained good correspondence of very early components, but their data does not show the usually reported large negative response at $75-100 \mathrm{msec}$, making the unusual agreement of scalp at cortex at 15-30 msec difficult to interpret.)

We believe that the differences between the scalp and deep recordings of the Celesia et al report just described may be attributable to the time difference between the two sets of recordings. It has been shown that the evoked potential in humans changes over time with no change in stimulus (Uttal, 1965). Moreover, it is difficult to estimate the traumatic effect of brain surgery on evoked potentials from the same surgical field. Thus, by recording deep and scalp signals simultaneously, we aimed at establishing the validity of the human auditory evoked response taken from scalp. We recorded from two unrestrained and unanesthetized cats while stimulating with aversively loud tonal "pips" and clicks. We reasoned that if a cat, irritated with noxious sounds, while free to move about, nevertheless generated identical scalp and cortical evoked potentials, then a cooperative human $S$ instructed to be still should be expected to produce responses as reliably free, on the average, of myogenic artifact. The results of similar simultaneously recorded scalp and deep placements in animals are contradictory: Rothenberg and Davis (1967) not only established a neural basis of the scalp record in chinchilla, but in fact, traced it to inferior colliculus, whereas Kern et al (1966) report no scalp response to acoustic stimulation in guinea pigs. It should be noted that the tissue and bone above the inferior colliculus in chinchilla is extremely thin, as Rothenberg and Davis (1967) point out; perhaps one cannot generalize from the results in this animal that scalp records are of neural origin.

\section{METHOD}

Cat 1 was chronically implanted (for other purposes) 5 months prior to this experiment with bipolar pairs of twisted .008-in. nichrome wire electrodes, uncoated at the ends. For this experiment, one member of each pair referenced to a sole stainless steel ground screw in frontal sinus was employed to yield monopolar placements comparable to the scalp electrode referenced to the same ground screw. The electrodes led to a multiconnector plug fastened to the skull. The coordinates of the active leads were AP:9, DV:7, L:18, AP:9, DV:3, L:18, and $\mathrm{AP}: 3, \mathrm{DV}: 7, \mathrm{~L}: 17$ (in the Horsley-Clark system), corresponding respectively to Auditory Areas I, II, and II Ep (posterior ecto-sylvian gyrus). Cat 2 was implanted chronically with stainless steel screw electrodes referenced to frontal sinus. The only electrode used in this animal was at AP:8, L:2 on the cortical surface (Visual Area II). These four placements were in areas acknowledged (Woolsey, 1961) to be responsive to auditory stimulation.

The amplification for all cortical leads was 10,000 ; it was doubled for the scalp lead, a silver-silver chloride cup fastened with collodion to the shaved scalp adjacent to the connector plug and medial to the pinna. The filters of the Grass P5 ac preamplifiers were set to pass signals between $1.5 \mathrm{~Hz}$ and $.1 \mathrm{kHz}$. Each separately amplified signal went to a separate channel of a Mnemotron CAT 400 B. The three cortical and one scalp signals of Cat 1 were recorded at the same time; the sole cortical and 
scalp signals of Cat 2 were likewise simultaneously recorded. The tonal "pip" was a 20-msec train of .1-msec square pulses amplified by an audio preamplifier and delivered to a Koss headphone mounted on the wall of the recording box (which allowed the animals about $9 \mathrm{cu} \mathrm{ft}$ of moving space). The click was obtained by reducing the width of the square pulse to $.06 \mathrm{msec}$ and triggering, rather than gating, the pulse former. The time between stimuli was $3 \mathrm{sec}$; they were $80 \mathrm{~dB}$ above electrophysiological threshold.

\section{RESULTS}

Although the cats were observed to shake their heads, investigate the headphone, and vocalize during the recording, the records of Figs. 1a, $1 \mathrm{~b}$, and $1 \mathrm{c}$ demonstrate the degree of superimposability of the simultaneously recorded deep and scalp potentials. A small primary component is observed in the A I record but not in the simultaneous scalp record. Neither is it present, however, in the other deep records; a primary component recordable from a primary area may be integrated out at higher levels. An expectable amplitude attenuation occurred in the scalp record. The largest negative component is uniquely steep in A II, but the scalp recording resembles the A I and II-Ep records more than they resemble the A II recording. These peculiarities notwithstanding, there would seem to be little doubt that these four records (from Cat 1) are due to the same neiral activity. Fig. 1c (from Cat 2) demonstrates a remarkable correspondence of the scalp and deep recordings from start to finish. It is observed that the cortical potential appears to lead the scalp potential by $2.3 \mathrm{msec}$, but this lead is consistent and in a reasonable direction. More important, it is seen that even the very early primary complex of both recordings contains what appear to be the same components. The latency of the early peak labelled $\mathrm{pl}$ is $13 \mathrm{msec}$ from stimulus onset, well into the early portion of the response where myogenic contamination is most expected. Not shown are the click-evolved responses of Cat 1 and the tone-evoked responses of Cat 2. These records are as those shown, leaving little doubt that the scalp and deep recordings contain the same information. Again, the record of Cat 2 shows identity of scalp and deep components having 12-msec latencies.

\section{DISCUSSION}

In view of these results, our concerns about myogenic interference in the scalp-recorded auditory evoked response have been reduced. Perhaps, had we employed manipulations specifically designed to activate muscle groups, the interference might have shown itself as it has in the work of Bickford et al (1964). Thus, we repeated, less elegantly, the manipulations of these reports, by recording from five human vertices (referenced

A
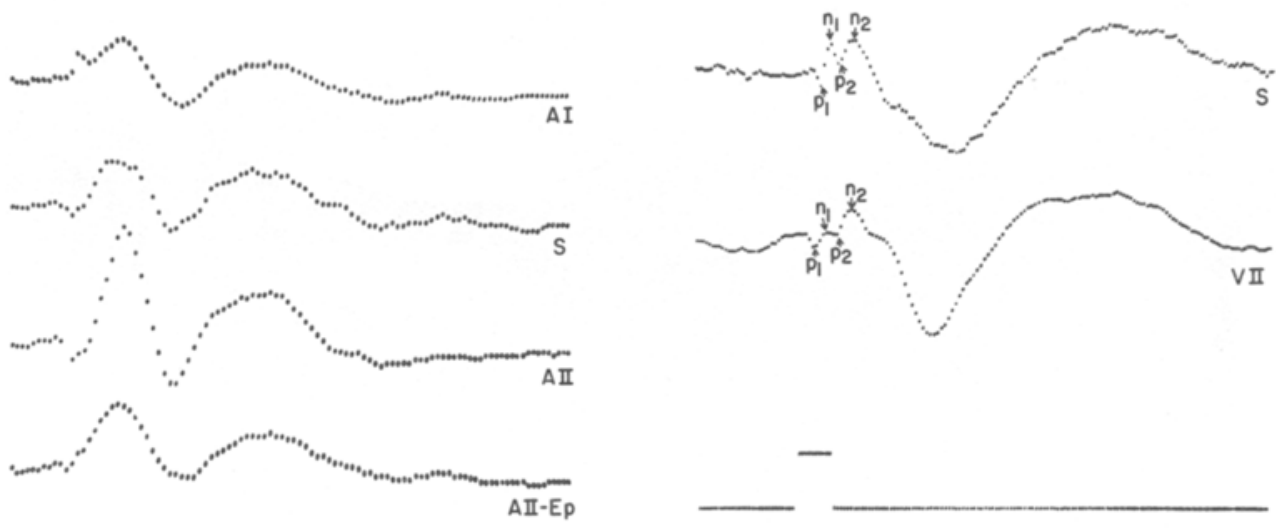

B
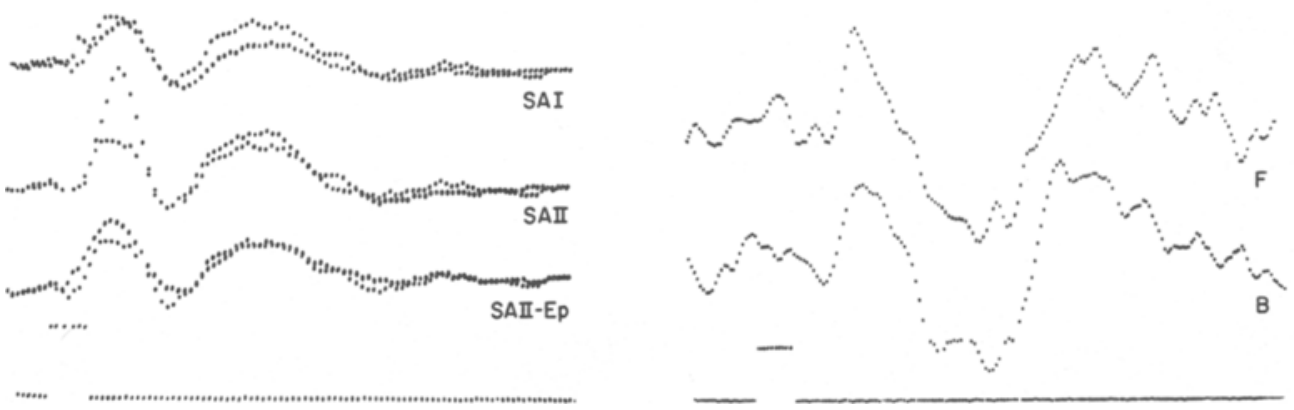

Fig. 1. (a) 100-sweep averages of responses from Auditory Areas I (AI), II (AII), II-posterior ectosylvian (AII-Ep), and scalp (S). Cat 1 responses to tonal "pips" are shown. 250-msec epoch. (b) The scalp response of Fig. 1a is shown superimposed upon the AI, AII, and AII-Ep traces. The leading edge of the calibration pulse is stimulus onset. The pulse width is $20 \mathrm{msec}$. The height of the pulse $=50 \mu \mathrm{V}$ and $25 \mu \mathrm{V}$ for cortical and scalp records, respectively. The pulse is for Fig. 1 a also. (c) Cat 2, S and Visual Area II ( $\left.V_{I I}\right)$ 100-sweep average responses to clicks. 500-msec epoch. Cal. pulse is as in Fig. 1 b. (d) Human S's 100-sweep average responses to tone in two conditions of neck muscle contraction as described in text. Cal. pulse $=5 \mu \mathrm{V}$ and $20 \mathrm{msec}$, marks stimulus onset. $\mathrm{F}=\mathrm{S}$ leaning forward; $B=$ backward. 
to mastoid) in two conditions of muscular contraction: In one condition, Ss pressed their heads backward into their chairs and in the other, they leaned forward, pressing their heads down against their palms, which were pushing back against their heads. Less intense stimulation was employed ( $40 \mathrm{~dB}$ above threshold) than with the cats, but otherwise the clicks and tones and recording conditions were as described before.

Shown in Fig. 1d are the records of a $S$ who complained of "muscle cramps and a stiff neck" following the session. The differences between the records obtained during different muscle contraction conditions seem just as attributable to the different recording times employed as to muscular activity. Certainly, the later components of the evoked potentials are obviously similar in any case, as they were in the four other Ss.

These results are not meant to imply that a human $S$ cannot produce myogenic potentials observable in single sweeps. Whether or not these responses can become systematic enough to average is another question. Certainly, the later components $(30 \mathrm{msec}$ or more in latency) seem to average without myogenic artifact. But even assuming the validity of an early "sonomotor" response, the presently more useful fact remains that a neural response recorded from scalp upon auditory stimulation can be reliably found; with suitable control for muscle noise (which seems simple enough to impose), this neural response, we feel, can be confidently utilized, as it has been for so long, in neural correlates studies, conditioning studies, and more recently, in hearing tests.

\section{REFERENCES}

BFRGAMINI, L., \& BERGAMASCO, B. In J. M. Sprague (Ed.), Cortical evoked potentials in man. Springfield, Ill.: Charles $\mathrm{C}$ Thomas Publishers, 1967.

BICKFORD, R. G., JACOBSON, J. L., \& CODY, D. T. T. Nature of averaged evoked potentials to sound and other stimuli in man. Annals of the New York Academy of Science, 1964, 192, 204-223.

CELESIA, G. C., BROUGHTON, R. J., RASMUSSEN, T., \& BRANCH, C. Auditory evoked responses from the exposed human cortex. Electroencephalography \& Clinical Neurophysiology, 1968, 24, 458-466.

ChATRIAN, G. E., PETERSEN, M. C., \& LAZARTE, J. A. Responses to clicks from the human brain. Electroencephalography \& Clinical Neurophysiology, 1960, 12, 479-489.

COOPER, R., WINTER, A. L., \& WALTER, W. G. Comparison of subcortical and scalp activity using chronically indwelling electrodes in man. Electroencephalography \& Clinical Neurophysiology, 1965, 18, 217-228.

DAVIS, H. S., ENGEBRETSON, M., LOWELL, E. L., MAST, T. SATTERFIELD, J., \& YOSHIE, N. Evoked responses to clicks recorded from the human scalp. Annals of the New York Academy of Science, $1964,112,224-225$

DOMINO, E. F., \& CORSSEN, G. Visually evoked response in anesthetized man with and without muscle paralysis. Annals of the New York Academy of Science, 1964, 112, 226-237.

DOMINO, E. F., MATSUOKA, S., WALTZ, J., \& COOPER, I. S. Simultaneous recordings of scalp and epidural somatosensoryevoked responses in man. Science, 1964, 165, 1199-1200.

FOX, S. S., \& RUDELL, A. P. Operant controlled neural event: A formal and systematic approach to electrical coding of behavior in the brain Science, 1968, 162, 1299-1301.

HIRSCH, J. F., PERTUISET, B., CALVET, J., BUISSON-FEREY, J., FISCHGOLD, G., \& SCHERRER, J. Étude de réponses électrocorticales obtenues chez l'homme par des stimulations somésthésiques et visuelles. Electroencephalography \& Clinical Neurophysiology, 1961, 13, 411-424.

JACOBSON, I. L., LAMBERT, E. H., \& BICKFORD, R. G. Nature of the averaged auricular response to sound stimulation in man. Electroencephalography \& Clinical Neurophy siology, 1964, 17, 608-611.

JASPER, H. H., LENDE, R., \& RASMUSSEN, T. Evoked potentials from the exposed somatosensory cortex in man. Journal of Nervous \& Mental Disorders, $1960,130,526-537$.

KATZMAN, R. The validity of the evoked response in man. Annals of the New York Academy of Science, 1964, 112, 238-240.

KERN, E. B., CODY, D. T. R., \& BICKFORD, R. G. Averaged evoked potentials to auditory stimuli recorded from dural electrodes in guinea pigs. Surgical Forum, 1966, 17, 465-466.

ROTHENBERG, S., \& DAVIS, H. Auditory evoked response in chinchilla: Application to animal audiometry. Perception \& Psychophysics, 1967, 2, 443-447.

RUHM, H., WALKER, E., \& FLANIGIN, H. Acoustically evoked potentials in man, mediation of early components. Laryngoscope, 1967 , 77, 806-822.

UTTAL, W. R. Do compound evoked potentials reflect psychological codes? Psychological Bulletin, 1965, 64, 377-391.

WOOLSEY, C. N. Organization of cortical auditory system. In W. A. Rosenblith (Ed.), Sensory communication. Cambridge, Mass.: M.I.T. Press, 1961. Pp. 235-258.

NOTE

1. Supported by USPHS grant MH 11834 to S. S. Fox.

2. Address: Department of Psychology, University of Iowa, Iowa City, Iowa 52240

(Accepted for publication January 21, 1969.) 